\title{
MATRIK
}

Jurnal Manajemen dan Teknik Industri-Produksi

Journal homepage: http://www.journal.umg.ac.id/index.php/matriks

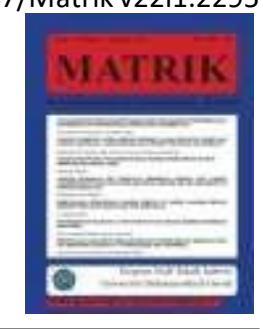

\section{Analisa Daerah Haz Besi Hollow Terhadap Variasi Elektroda}

\author{
Minto $^{1 *}$, Andhika Mayasari ${ }^{2}$, Basuki $^{3}$ \\ Program Studi Teknik Industri ${ }^{1 * 2}$, Fakultas Teknik, Universitas Hasyim Asy'ari \\ Program Studi Teknik Mesin ${ }^{3}$, Fakultas Teknik, Universitas Hasyim Asy'ari \\ Jl.Irian Jaya No.55, Cukir, Diwek, Jombang, Jawa Timur, Indonesia \\ mintoiriuha@gmail.com ${ }^{1 *}$, andhikamayasari@gmail.com ${ }^{2}$, Ukibas02its@gmail.com ${ }^{3}$
}

INFO ARTIKEL

Jejak Artikel :

Upload artikel

15 Februari 2020

Revisi

O4 September 2021

Publish

30 September 2021

\section{Kata Kunci :}

Daerah HAZ, elektroda, pengujian bahan

\section{ABSTRAK}

Penelitian ini bertujuan untuk mengetahui angka kekerasan Brinell (HRB) pada daerah lasan mulai dari logam lasan (weld metal) sampai logam induk (Parent metal) dan untuk mengetahui perbedaankekerasan Brinell pada daerah HAZ sebelum dan sesudah dilas dengan menggunakan jenis variasi elektroda. Proses pelaksanaan pengelasan besi Hollow dilaksanakan di BLK Jombang, sementara untuk pengujian Brinel dilakukan di PT Tjokro Bersaudara Gresik Jl. Raya Veteran Km.01. No.126 Gresik. Eksperimen ini dilakukan pada besi Hollow dengan ukuran panjang keseluruhan $240 \mathrm{~mm}$, tebal $1 \mathrm{~mm}$ dan lebar $25 \mathrm{~mm}$ dan membandingkan perbedaan antara nilai kekerasan Brinell ( HRB ) dengan menggunakan variasi elektroda jenis RD 260 dengan RD 460pada pengelasan busur nyala listrik. Pengambilan data dilakukan pada specemen elektroda RD 260 dan RD 460 dengan 20 titik pengujian pada kemudian diambil rata-rata nilai kekerasannya.Berdasarkan Hasil Report Of Hardness Test dapat disimpulkan sebagai berikut : pada Titik Uji 4 adalah 104 HRB dengan jarak penetrasi daerah lasan dari sumbu las ( $20 \mathrm{~mm}$ ). terlihat adanya kenaikan kekerasan HRB secara drastis pada setiap specement. Perbedaan terbesar terjadi pada titik B sebesar 426,5 HRB. Daerah las ini mengalami kenaikan rata-rata nilai kekerasan sebesar 104 HRB .Sementara pada Titik Uji 6 adalah -12.5 HRB dengan jarak penetrasi daerah lasan dari sumbu las ( 30 $\mathrm{mm}$ ). terlihat adanya kenaikan kekerasan HRB paling rendah pada setiap specement. Perbedaan terbesar terjadi pada titik A sebesar 337,5 HRB. Daerah las ini mengalami penurunan rata-rata nilai kekerasan sebesar -12.5 HRB. Pada penelitian besi Hollow yang dilas dengan busur nyala listrik dengan arus 70 A diperoleh hasil bahwa pada daerah lasan mulai dari sumbu las ( $\mathrm{O} \mathrm{mm}$ ) sampai pada jarak $50 \mathrm{~mm}$ terdapat perbedaan yang signifikan nilai kekerasan Brinell. 


\section{Pendahuluan}

Teknik pengelasan banyak dipergunakan secara luas dalam proses penyambungan, salah satunya yaitu pada konstruksi bangunan dan konstruksi mesin [1][2]. Luasnyateknologi pengelasan ini disebabkan karena konstruksi bangunan dan konstruksi mesin menjadi lebih ringan dan proses pembuatanya juga lebih sederhana sehingga biaya keseluruhanya lebih murah[3][4].

Dalam perencanaan konstruksi bangunan dan konstruksi mesin dengan mengunakan sambungan las harus direncanakan pula cara pengelasan, cara pemeriksaan, bahan las dan jenis las yang akan digunakan berdasarkan fungsi dari bagian-bagian bangunan atau mesin yang dirancang, apabila pada pengelasan kurang tepat akan mengakibatkan kerusakan- kerusakan seperti keretakan, mudah patah, atau mekanis kimianya yang rusak[5][6]. Kemungkinan besar kerusakan-kerusakan pengelasan terjadi pada daerah pengaruh panas (daerah lasan)[7][8][9].

Dalam proses pengelasan bisa dilakukan dengan teknik-teknik tertentu sehingga didapatkan hasil las yang baik. Ada beberapa macam jenis dan proses pengelasan antara lain; pengelasan busur listrik terlindung adalah bentuk pengelasan yang mengunakan busur nyala listrik terlindung yang terdapat pada kawat elektroda yang dibungkus dengan flux. Proses pemindahan logam elektroda ini terjadi pada saat elektroda mencair yang disebabkan oleh panas dari busur listrik pada waktu adanya perpindahan arus listrik dari batang elektroda ke benda kerja lewat udara[10]. Pengelasan mempunyai peranan yang sangat penting dalam pembangunan suatu konstruksi karena pengelasan mempunyai kemampuan untuk memotong dan menyambung benda kerja yang tebal maupun tipis, sehingga pembuatanya lebih sederhana dan biaya keseluruhanya lebih murah. Disamping pengelasan banyak segimanfaatnya, pengelasan juga mempunyai dampak negatifnya khususnya terhadap kesehatan[11][12].

Hasil penelitian ini diharapkan dapat memberikan kontribusi terhadap tukang las khususnya pada besi Hollow dan dapat dijadikan model pengukuran jenis elektroda mana yang cocok Berdasarkan penjelasan diatas maka peneliti akan menganalisa daerah lasan HAZ pada besi hollow dan dapat menjadi rujukan yang baik untuk meningkatkan hasil las lebih cepat[13][14].
Beberapa penelitian yang berkaitan dengan daerah Haz pada besi Hollow diantaranya: Analisa Ketangguhan Dan Struktur Mikro Pada Daerah Las Dan Haz Hasil Pengelasan Tungsten Inert Gas ( Tig ) Pada Aluminium Alloy 6061 Disusun Oleh : Alfian Iman Departemen Teknik Mesin Fakultas Teknik Universitas Sumatera Utara Medan 2016. Hasil dari uji struktur mikro menunjukkan bahwa struktur butiran Al pada daerah HAZ menyatu dengan aluminium primer $(\alpha$-al) dan butiran $\mathrm{Si}$ membentuk paduan Si primer diantara $\alpha$-al. Hasil rata-rata uji impak pada daerah HAZ variasi kuat arus 90 ampere, energi yang diserap 34,266 joule dan nilai impak 0,342 Joule/ $\mathrm{mm}^{2}$, pada kuat arus 100 ampere, energi yang diserap 27,074 joule dan nilai impak $0,270 \mathrm{Joule} / \mathrm{mm}^{2}$, dan pada kuat arus 110 ampere, energi yang diserap 20,214 joule dan nilai impak 0,202 Joule $/ \mathrm{mm}^{2}$.dari hasil pengujian yang dilakukan disimpulkan[15]

\section{Besi Hollow}

Besi hollow merupakan salah satu besi yang berbentuk pipa kotak. . Besi hollow ini dapat dinyatakan sangat unggul dan baik digunakan dalam pemasangan rangka besi plafon serta dinding partisi rumah, gedung, dan lain sebagainya.Sebenarnya sebutan 'besi holo' itu kurang tepat. Sebutan yang tepat adalah 'besi hollow. Karena bentuknya yang seperti pipa kotak yang lurus, maka banyak digunakan jugasebagaimaterial interior dan furniture berga ya minimals yang sedang trendy saat ini.

\section{Las elektroda terbungkus.}

Las elektroda terbungkus adalah cara pengelasan pada masa kini. Dalam cara pengelasan ini digunakan kawat elektroda logam yang terbungkus dalam fluxs. Busur listrik terbentuk diantara dua logam induk dan ujung elektroda. Karena panas dari busur ini maka logam induk dan ujung elektroda tersebut mencair dan kemudian membeku bersama.

\section{Daerah Lasan ( HAZ)}

Logam akan mengalami pengaruh pemanasan akibat pengelasan dan mengalami perubahan struktur mikro disekitar daerah lasan. Bentuk struktur mikro bergantung pada temperatur tertinggi yang dicapai pada pengelasan, kecepatan pengelasan dan laju pendinginan daerah lasan. Daerah logam yang mengalami perubahan struktur mikro akibat mengalami pemanasan karena pengelasan disebut daerah pengaruh panas (DPP), atau Heat Affected Zone. 


\section{Uji Kekerasan Brinell}

Metode uji kekerasan yang diajukan oleh J.A. Brinell pada tahun 1900 ini merupakan uji kekerasan lekukan yang pertama kali banyak digunakan serta disusun pembakuannya (Dieter, 1987). Uji kekerasan ini berupa pembentukan lekukan pada permukaan logam memakai bola baja yang dikeraskan yang ditekan dengan beban tertentu. Beban diterapkan selama waktu tertentu, biasanya 30 detik, dan diameter lekukan diukur dengan mikroskop, setelah beban tersebut dihilangkan. Permukaan yang akan dibuat lekukan harus relatif halus, rata danbersih dari debu atau kerak. Angka kekerasan brinell (BHN) dinyatakan sebagai beban $\mathrm{P}$ dibagi luas permukaan lekukan. Pada prakteknya, luas ini dihitung dari pengukuran mikroskopik panjang diameter jejak. BHN dapat ditentukan dari persamaan berikut:

$$
B H N=\frac{P}{(\pi D / 2)\left(D-\sqrt{D^{2}-d^{2}}\right)}=\frac{2 P}{(\pi D)\left(D-\sqrt{D^{2}-d^{2}}\right)} .
$$

\section{Metode Penelitian}

\subsection{Jenis Penelitian}

Penelitian ini adalah penelitian eksperimen, yang diteliti adalah daerah lasan pada pengelasan datar dengan mengunakan pengelasan busur listrik. Daerah lasan tersebut yaitu terdiri dari daerah logam las, daerah HAZ dan daerah logam induk. Jenis bahan yang dilas adalah Besi hollow kemudian bahan tersebut diuji Kekerasan Brinell (HRB) untuk mengetahui perbedaannya. Sampel yang digunakan pada penelitian ini adalah besi hollow berbentuk kotak berlubang yang banyak beredar di pasaran pada saat ini. Sebagai sampel, adalah besi hollow gavalum dengan ukuran panjang $120 \mathrm{~mm}$, tebal $1 \mathrm{~mm}$ dan lebar $25 \mathrm{~mm}$.

\subsection{Tempat dan Waktu Penelitian}

\section{Tempat penelitian}

Tempat melaksanakan penelitian dilaksanakan di BLK jombang dan PT Tjokro Bersaudara Gresik Jawa Timur.sedangkan obyek penelitian adalah daerah HAZ pada besi Hollow.

\section{Waktu Penelitian \\ a. Waktu persiapan.}

Dalam melakukan persiapan penelitian yaitu di mulai dengan melakukan observasi awal untuk menentukan obyek yang ada di lapangan. Setelah itu untuk mendapatkan data yang diperlukan yaitu dengan jalan melakukan percobaan terhadap benda kerja dalam proses pengujian Kekerasan Brinell (HRB).

\section{b. Waktu pengumpulan data}

Tahap pengumpulan data dilakukan dengan mengadakan eksperimen dari obyek penelitian. Selanjutnya dari data-data tersebut dikumpulkan untuk dilakukan pengolahan data.

\section{Metode Pengumpulan Data}

Metode pengumpulan data dalam penelitian ini adalah sebagai berikut :

\subsection{Metode Literatur}

Metode literatur dilaksanakan dengan jalan menbaca buku-buku yang berhubungan dengan materi penelitian.

\subsection{Metode Observasi}

Metode observasi dilaksanakan dengan melakukan pengamatan langsung terhadapbahan kerja, perlengkapan, dan proses pengelasan yang digunakan.

\subsection{Metode Eksperiment}

Metode eksperimen dilaksanakan untuk mencari dan mengumpulkan data serta menyusunnya dengan jalan melakukan percobaan terhadap benda kerja dalam proses pengujian kekerasan Brinell (HRB). Tahapan yang dipakai oleh penelitian, antara lain:

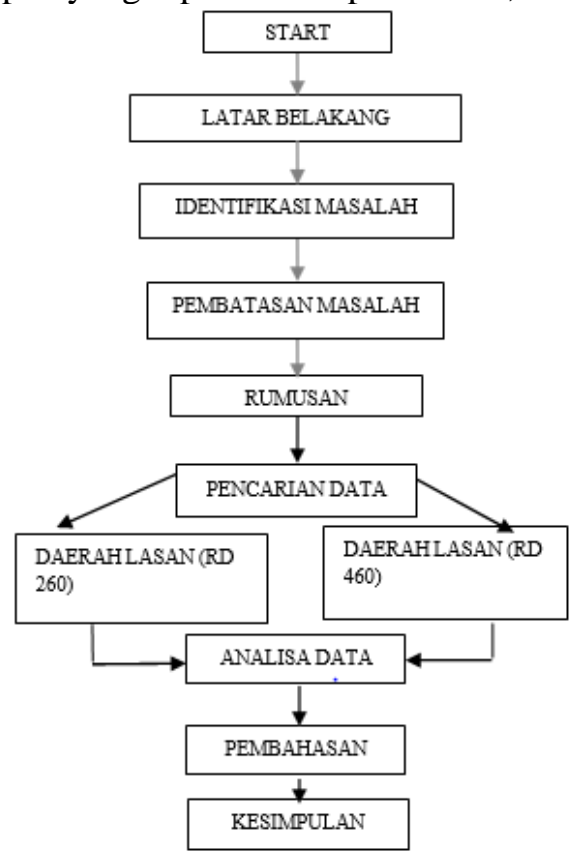

Gambar 1. Tahapan Penelitian 


\subsection{Tahap pelaksanaan menyiapkan bahan besi Hollow dan peralatan}

a. Bahan

Bahan yang digunakan pada penelitian ini adalah besi hollow yang ada dipasaran atau took besi terdekat .

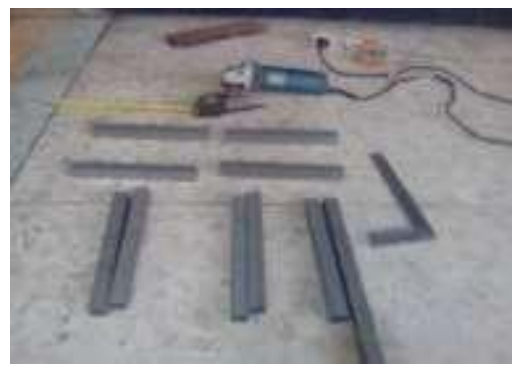

Gambar 2. Pemotongan besi hollow Bahan di potong-potong dengan ukuran panjang $120 \mathrm{~mm}$, tebal $1 \mathrm{~mm}$ dan lebar $25 \mathrm{~mm}$. Sebanyak 5 potong, kemudian di bentuk kampuh I tunggal, yang di buat berpasangan, bentuk dari kampuh tersebut seperti pada gambar berikut :

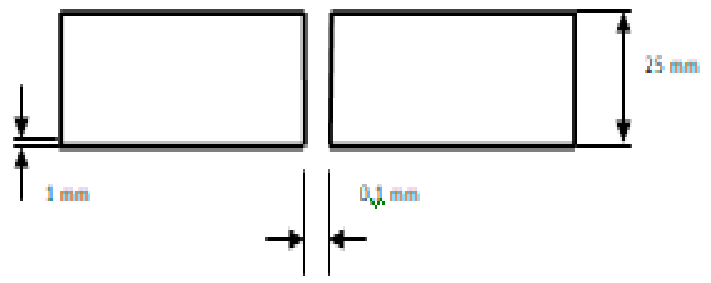

Gambar 3. Bentuk kampuh I tertutup

\section{b. Peralatan}

Peralatan yang digunakan dalam eksperimen ini adalah sama antara lain :

\section{Portable Hardness Tester :}

Merk : SP Tech PHTD

Buatan : japan

Weight :100 gram.

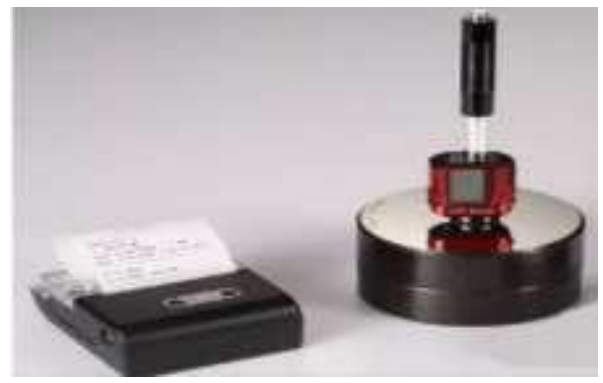

Gambar 4. Portable Hardness Tester SP Tech
PHTD adalah alat Uji kekerasan portable merupakan salah satu cara untuk mengetahui kekuatan atau ketahanan suatu (bahan) material.

2.Kawat elektroda las dengan data sebagaiberikut :

$\begin{array}{ll}\text { Specification } & \text { AWS A5.1 E } 6013 \\ \text { JIS Z } 3211 \text { D4313 }\end{array}$

Type of covoring : HIGH TITANIA

Use : Mild Steel.

Diameter/Length : 2,0 mm / $300 \mathrm{~mm}$

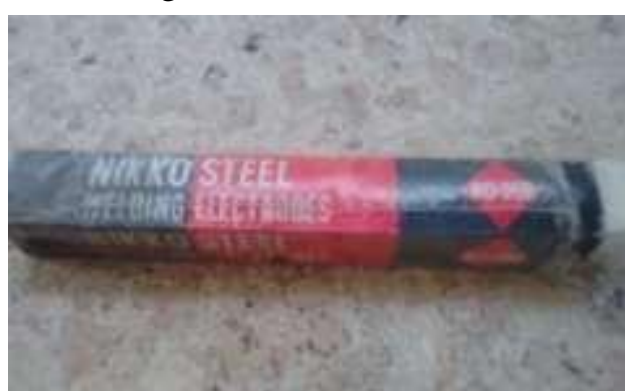

Gambar 5. RD - 260

Specification : AWS A5.1 E 6013

ISO 2560 A.E 35 O R

JIS Z 3211 D4313

Type of covoring : HIGH TITANIA

Use : Mild Steel.

Diameter/Length : 2,0 mm / $300 \mathrm{~mm}$

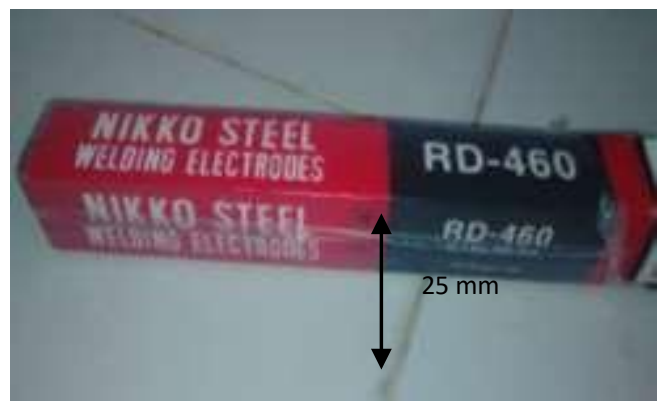

Gambar 6. RD - 460

3. Mesin las yang digunakan :

Merk : EMCO MAIR Ges .m.b.

Hallein Fabrik Fur Special Maschinen

Buatan : AUSTRIA

Type : M 4 U - 025

- Alat ukur jangka sorong.

- Arus yang digunakan yaitu $70 \mathrm{~A}$.

- Pengelasan dilakukan oleh orang yang ahli dibidang pengelasan dan mempunyai sertifikat kompentensi keahlian dibidang pengelasan.

Portable Hardness Tester Merk SP Tech 


\subsection{Tahap pengelasan besi hollow}

Sebelum dilakukan proses pengelasan harus diperhatikan prosedur pengelasan, tujuannya adalah untuk menghindari kesalahan dalam pengelasan. Prosedur pengelasan adalah suatu perencanaan untuk pelaksanaan pengelasan yang meliputi cara pembuatan konstruksi las yang sesuai dengan rencana dan spesifikasi dengan menentukan semua yang diperlukan dalam pelaksanaan pengelasan

Setelah semua persiapan telah terpenuhi maka pelaksanaan pengelasan mulai dilakukan, untuk pengelasan bahan spesimen dengan bentuk kampuh I tunggal ini, pertama-tama dilakukan pengancingan bahan di masing- masing ujung bahan agar jarak antar benda yang dilas tidak berubah. Kemudian pelaksanaan pengelasan dilakukan se kali pengisian.

Setelah proses pengelasan ini selesai selanjutnya dilakukan pembersihan permukaan agar kerak-kerak dari pengelasan yang menempel pada bahan bersih, kegiatan ini merupakan kegiatan finishing dari proses pengelasan. Jarak lasan pada proses pengelasan busur nyala listrik $70 \mathrm{~A}$ dari sumbu las $0 \mathrm{~mm}$ sampai $25 \mathrm{~mm}$. Logam yang digunakan adalah besi hollow dengan ukuran panjang $120 \mathrm{~mm}$, tebal $1 \mathrm{~mm}$ dan lebar $25 \mathrm{~mm}$. Jadi bahan yang digunakan dan ukuran bahan untuk semua proses penelitian ini adalah sama.

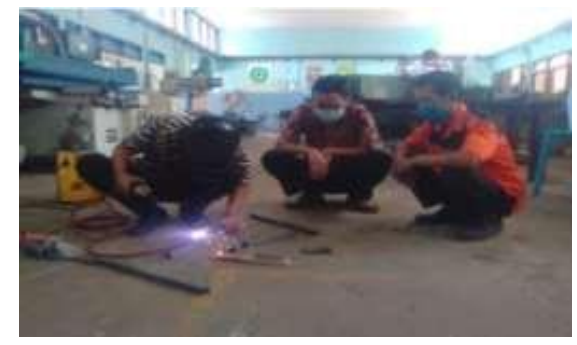

Gambar 7. proses pengelasan

\section{a. Tahap pelaksanaan menandai titik}

padabesi hollow yang akan dijui :

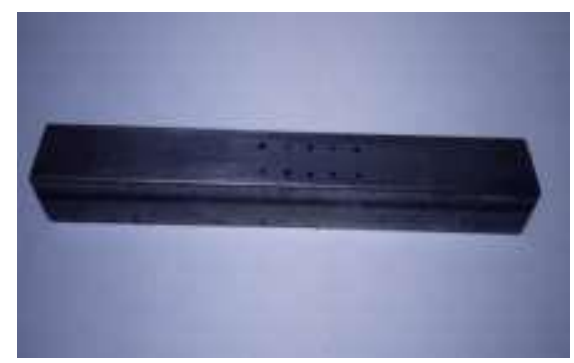

Gambar 8. Besi hollow diberi tanda titik uji

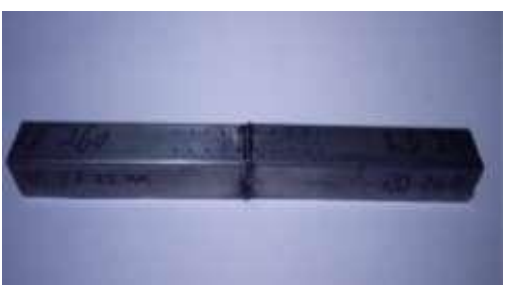

Gambar 9. Besi hollow dilas RD 260

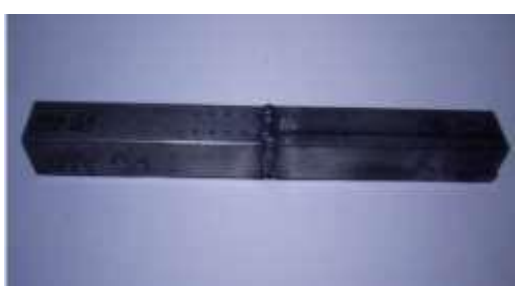

Gambar 10. Besi hollow dilas RD 460

\section{b.Tahap pelaksanaan mengujian daerah}

\section{HAZ menggunakan pengujian brinell}

Kekerasan didefinisikan sebagai ketahanan bahan terhadap deformasi plastis yang biasanya dilaksanakan dengan cara penetrasi sehingga menghasilkan jejak atau lekukan pada permukaan benda yang diuji.

Pengujian kekerasan bahan dengan metode Brinell merupakan salah satu metode pengujian kekerasan yang banyak dipakai. Uji kekerasan Brinell dilakukan dengan cara menekankan sebuah bola baja berdiameter $10 \mathrm{~mm}$ pada permukaan benda uji (spesimen) dengan gaya atau beban $3000 \mathrm{kgf}$ untuk besi dan baja, serta dengan periode waktu tertentu (biasanya 10 - 15 detik).

Hasil dari penekanan indentor atau penetrator yang berupa bola baja yang dikeraskan ini adalah jejak atau lekukan berbentuk tembereng bola pada permukaan spesimen.
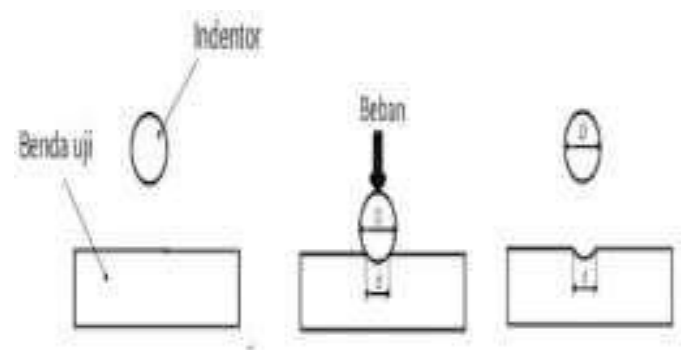

Gambar 11. Proses penekanan benda uji 


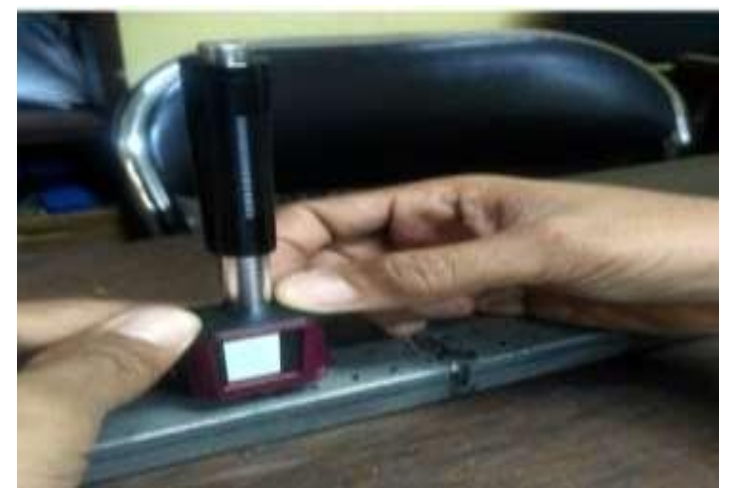

Gambar 12 .Pengujian Brinell (HRB)

Selanjutnya untuk mendapatkan nilai kekerasan dari benda uji, diameter jejak tersebut diukur dengan menggunakan sebuah miroskop. Pengukuran dilakukan pada dua buah diameter yang saling tegak lurus atau membentuk sudut siku-siku $\left(90^{\circ}\right)$, yang diambil rata-ratanya

\section{Hasil dan Pembahasan}

Dalam Penelitian ini dilakukan analisis terhadap daerah lasan pada pengelasan busur nyala listrik terhadap kekerasan Brinell (HRB) untuk Besi Hollow. Daerah lasan tersebut yaitu terdiri dari daerah logam las, daerah HAZ dan daerah logam induk.

Data hasil pengujian kekerasan Brinell ( HRB) pada besi hollow sebelum dilas dapat dilihatpada tabel dibawah ini :

Tabel 1. Uji HRB pada besi hollow sebelumdilas

\begin{tabular}{|c||c|c||}
\hline \multicolumn{1}{|c|}{ No. } & \multicolumn{2}{|c|}{ HRB } \\
\cline { 2 - 3 } & A & B \\
\hline \hline 1 & 247 & 359 \\
\hline 2 & 286 & 376 \\
\hline 3 & 295 & 390 \\
\hline 4 & 257 & 375 \\
\hline 5 & 278 & 362 \\
\hline 6 & - & - \\
\hline 7 & - & - \\
\hline 8 & - & - \\
\hline 9 & - & - \\
\hline 10 & - & - \\
\hline
\end{tabular}

a. Data hasil pengujian kekerasan Brinell ( HRB) pada besi hollow setelah dilas menggunakan elektroda E6013 / RD 260 dapat dilihat pada tabel dibawah ini :

Tabel 2. Uji HRB pada besi hollow setelah dilas RD 260

\begin{tabular}{||c||c|c|}
\hline \multicolumn{1}{|c|}{ No. } & \multicolumn{2}{|c|}{ HRB } \\
\cline { 2 - 3 } & A & B \\
\hline 1 & 295 & 272 \\
\hline 2 & 287 & 300 \\
\hline 3 & 319 & 344 \\
\hline 4 & 345 & 300 \\
\hline 5 & 375 & 338 \\
\hline 6 & 326 & 369 \\
\hline 7 & 355 & 369 \\
\hline 8 & 283 & 345 \\
\hline 9 & 257 & 376 \\
\hline 10 & 337 & 380 \\
\hline
\end{tabular}

b. Data hasil pengujian kekerasan Brinell ( HRB) pada besi hollow setelah dilas menggunakan elektroda E6013 / RD 460 dapat dilihat pada tabel dibawah ini :

Tabel 3. Uji HRB pada besi hollow setelah dilas RD 460

\begin{tabular}{||c||c|c|}
\hline \multicolumn{1}{|c|}{ No. } & \multicolumn{2}{|c|}{ HRB } \\
\cline { 2 - 3 } & A & B \\
\hline 1 & 323 & 380 \\
\hline 2 & 339 & 367 \\
\hline 3 & 360 & 441 \\
\hline 4 & 403 & 450 \\
\hline 5 & 368 & 423 \\
\hline 6 & 323 & 327 \\
\hline 7 & 379 & 417 \\
\hline 8 & 350 & 427 \\
\hline 9 & 338 & 365 \\
\hline 10 & 320 & 353 \\
\hline
\end{tabular}


Jika dilihat dari tabel diatas, maka nilaikekerasan Brinell ( HRB ) pada daerah lasan pada besi Hollow setelah dilas menggunakan elektroda RD 460 lebih tinggi kekerasannya dari pada menggunakn elektroda RD 260 dengan pengelasan busur nyala listrik.

Hal ini dapat dilihat dari nilai rata-rata kekerasan Brinell ( HRB)

Tabel 4. Uji HRB pada besi hollowsetelah dilas RD 460 dan RD 460

\begin{tabular}{|c|c|c|c|c|}
\hline \multicolumn{5}{|c|}{$\begin{array}{c}\text { Tingkat Kekerasan Daerah Lasan dari } \\
\text { Sumbu Las }\end{array}$} \\
\hline \multirow[b]{2}{*}{$\begin{array}{c}\text { Titik } \\
\text { Uji }\end{array}$} & \multirow{2}{*}{$\begin{array}{c}\text { Variasi } \\
\text { Elektroda }\end{array}$} & \multicolumn{2}{|c|}{ SSPC } & \multirow[b]{2}{*}{ Rata ratc } \\
\hline & & A & B & \\
\hline \multirow{2}{*}{1} & RD 260 & 295 & 272 & 283.5 \\
\hline & RD 460 & 323 & 380 & 351.5 \\
\hline \multirow{2}{*}{2} & RD 260 & 287 & 300 & 293.5 \\
\hline & RD 460 & 339 & 367 & 353 \\
\hline \multirow{2}{*}{3} & RD 260 & 319 & 344 & 331.5 \\
\hline & RD 460 & 360 & 441 & 400.5 \\
\hline \multirow{2}{*}{4} & RD 260 & 345 & 300 & 322.5 \\
\hline & RD 460 & 403 & 450 & 426.5 \\
\hline \multirow{2}{*}{5} & RD 260 & 375 & 338 & 356.5 \\
\hline & RD 460 & 368 & 423 & 395.5 \\
\hline \multirow{2}{*}{6} & RD 260 & 326 & 349 & 337.5 \\
\hline & RD 460 & 323 & 327 & 325 \\
\hline \multirow{2}{*}{7} & RD 260 & 355 & 389 & 372 \\
\hline & RD 460 & 379 & 417 & 398 \\
\hline \multirow{2}{*}{8} & RD 260 & 283 & 345 & 314 \\
\hline & RD 460 & 350 & 427 & 388.5 \\
\hline \multirow{2}{*}{9} & RD 260 & 257 & 376 & 316.5 \\
\hline & $\mathrm{RD} 460$ & 338 & 365 & 351.5 \\
\hline \multirow{2}{*}{10} & RD 260 & 337 & 380 & 358.5 \\
\hline & RD 460 & 320 & 353 & 336.5 \\
\hline
\end{tabular}

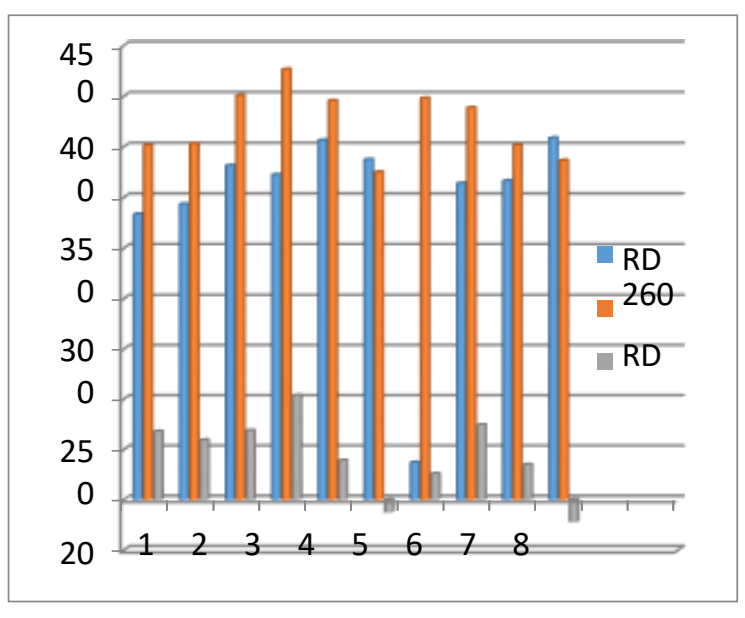

Gambar 13. Grafik Perbandingan Kekerasan Brinell (HRB) pada jarak Penetrasi $5 \mathrm{~mm}-50 \mathrm{~mm}$ padadaerah lasan (HAZ)

Pada Titik Uji 1 adalah 168 HRB dengan jarak penetrasi daerah lasan dari sumbu las ( $5 \mathrm{~mm}$ ). terlihat adanya kenaikan kekerasan HRB secara drastis pada setiap specement. Perbedaanterbesar terjadi pada titik B sebesar 351,5 HRB. Daerah las ini mengalami kenaikan rata-rata nilai kekerasan sebesar 168 HRB.

Pada Titik Uji 2 adalah 59.5 HRB dengan jarak penetrasi daerah lasan dari sumbu las ( $10 \mathrm{~mm}$ ). terlihat adanya kenaikan kekerasan HRB secara drastis pada setiap specement. Perbedaanterbesar terjadi pada titik B sebesar 353 HRB. Daerah las ini mengalami kenaikan rata-rata nilai kekerasan seb

Pada Titik Uji 3 adalah 69 HRB dengan jarak penetrasi daerah lasan dari sumbu las ( $15 \mathrm{~mm}$ )esar 59.5 HRB. terlihat adanya kenaikan kekerasan HRB secara drastis pada setiap specement. Perbedaan terbesar terjadi pada titik B sebesar 400,5 HRB. Daerah las ini mengalami kenaikan rata-rata nilai kekerasansebesar 69 HRB.

Pada Titik Uji 4 adalah 104 HRB dengan jarak penetrasi daerah lasan dari sumbu las ( $20 \mathrm{~mm}$ ). terlihat adanya kenaikan kekerasan HRB secara drastis pada setiap specement. Perbedaanterbesar terjadi pada titik B sebesar 426,5 HRB. Daerah las ini mengalami kenaikan rata-rata nilai kekerasan sebesar 104 HRB. 
Pada Titik Uji 5 adalah 39 HRB dengan jarak penetrasi daerah lasan dari sumbu las ( $25 \mathrm{~mm}$ ). terlihat adanya kenaikan kekerasan HRB secara drastis pada setiap specement. Perbedaan terbesar terjadi pada titik B sebesar 395,5 HRB. Daerah las ini mengalami kenaikan rata-rata nilai kekerasan sebesar $39 \mathrm{HRB}$.

Pada Titik Uji 6 adalah -12.5 HRB dengan jarak penetrasi daerah lasan dari sumbu las ( 30 $\mathrm{mm}$ ). terlihat adanya kenaikan kekerasan HRB secara drastis pada setiap specement. Perbedaan terbesar terjadi pada titik A sebesar 337,5 HRB. Daerah las ini mengalami penurunan rata-rata nilai kekerasan se

Pada Titik Uji 7 adalah 26 HRB dengan jarak penetrasi daerah lasan dari sumbu las ( 35 mm )besar -12.5 HRB. terlihat adanya kenaikan kekerasan HRB secara drastis pada setiap specement. Perbedaan terbesar terjadi pada titik B sebesar 398 HRB. Daerah las ini mengalami penurunan rata-rata nilai kekerasan sebesar 26 HRB.

Pada Titik Uji 8 adalah 74.5 HRB dengan jarak penetrasi daerah lasan dari sumbu las ( 40 mm ). terlihat adanya kenaikan kekerasan HRB secara drastis pada setiap specement. Perbedaan terbesar terjadi pada titik B sebesar 388.5 HRB. Daerah las ini mengalami penurunan rata-rata nilai kekerasan sebesar 74.5 HRB.

Pada Titik Uji 9 adalah 35 HRB dengan jarak penetrasi daerah lasan dari sumbu las ( $45 \mathrm{~mm}$ ). terlihat adanya kenaikan kekerasan HRB secara drastis pada setiap specement. Perbedaan terbesar terjadi pada titik B sebesar 351.5 HRB. Daerah las ini mengalami penurunan rata-rata nilai kekerasan sebesar $35 \mathrm{HRB}$

Pada Titik Uji 10 adalah -22 HRB dengan jarak penetrasi daerah lasan dari sumbu las ( 50 mm ). terlihat adanya kenaikan kekerasan HRB secara drastis pada setiap specement. Perbedaan terbesar terjadi pada titik A sebesar 355.5 HRB. Daerah las ini mengalami penurunan rata-rata nilai kekerasan sebesar -22 HRB.

\section{Kesimpulan dan Saran}

Hasil dari analisa dan pembahasan yang berdasarkan pengamatan dan pengujian nilai kekerasan HRB pada daerah lasan untuk

besi hollow setelah dilas menggunakan elektroda RD 460 lebih tinggi kekerasannya dari pada menggunakan elektroda RD 260 dengan pengelasan busur nyala listrik.Pengujian dilakukan pada daerah HAZ dengan 10 Titik Uji dari sumbu las pada besi hollow dengan pengelasan busur nyala listrik.

Kedua specement tersebut menunjukan tingkat kekerasan yang makin meningkat kearah sumbu las ( weld metal), dan makin menurun kearah logam induk ( parent metal).

Berdasarkan analisa tersebut maka dapat di simpulkan sebagai berikut :

Perbedaan nilai kekerasan HRB pada besi Hollow yang menggunakan elektroda RD 460 dan elektroda RD 260

\begin{tabular}{|c|c|c|c|}
\hline $\begin{array}{c}\text { Titik } \\
\text { Uji }\end{array}$ & RD 260 & RD 460 & selisih \\
\hline $\mathbf{1}$ & 283.5 & 351.5 & 68 \\
\hline $\mathbf{2}$ & 293.5 & 353 & 59.5 \\
\hline $\mathbf{3}$ & 331.5 & 400.5 & 69 \\
\hline $\mathbf{4}$ & 322.5 & 426.5 & 104 \\
\hline $\mathbf{5}$ & 356.5 & 395.5 & 39 \\
\hline $\mathbf{6}$ & 337.5 & 325 & -12.5 \\
\hline $\mathbf{7}$ & 372 & 398 & 26 \\
\hline $\mathbf{8}$ & 314 & 388.5 & 74.5 \\
\hline $\mathbf{9}$ & 316.5 & 351.5 & 35 \\
\hline $\mathbf{1 0}$ & 358.5 & 336.5 & -22 \\
\hline
\end{tabular}

Perlu dilakukan penelitian lebih lanjut tentang pengujian kekerasan Brinell (HRB). Sehingga ada beberapa saran sehubungan dengan hal ini :

1. Perlu diadakan penelitian dengan mengunakan jenis mesin yang lain. 
2. Perlu diadakan penelitian pada jarak penekanan ( penetrasi ) daerah lasan kearah sumbu lasan yang lebih dekat .

3. Perlu diadakan variabel-variabel lain seperti arus lebih tinggi, elektroda lebih

besar atau mengunakan pendinginan yang berbeda

\section{Daftar Pustaka}

[1] Risma Dwi Atmajayani, "Implementasi Penggunaan Aplikasi AutoCAD dalam Meningkatkan Kompetensi Dasar Menggambar teknik bagi Masyarakat," BRILIANT J. Ris. dan Konseptual, vol. 3, no. 2, pp. 184-189, 2018, doi: 10.1088/1751-8113/44/8/085201.

[2] D. Prayitno, H. D. Hutagalung, and D. P. B. Aji, "Pengaruh Kuat Arus Listrik Pengelasan Terhadap Kekerasan Lapisan Lasan pada Baja ASTM A316," J. Din. Vokasional Tek. Mesin, vol. 3, no. 1, pp. 16, 2018, doi: 10.21831/dinamika.v3i1.19109.

[3] H. Dahlan, "Pengaruh Variasi Beban Indentor Micro Hardness," no. 23.

[4] S. Jokosisworo, "Pengaruh Besar Arus Listrik Dengan Menggunakan Elektroda Smaw Terhadap Kekuatan Sambungan Las Butt Joint Pada Plat Mild Steel," Kapal, vol. 6, no. 2, pp. 118-122, 2012, doi: 10.12777/kpl.6.2.118-122.

[5] D. G. Karalis, V. J. Papazoglou, and D. I. Pantelis, "Mechanical response of thin SMAW arc welded structures:

Experimental and numerical investigation," Theor. Appl. Fract. Mech., vol. 51, no. 2, pp. 87-94, 2009, doi: 10.1016/j.tafmec.2009.04.004.

[6] K. N. Syahputra, "Analisa Kegagalan Sambungan Las Pada Tiang Penyangga Dermaga," J. Ilm. Semesta Tek., vol. 18, no. 1, pp. 1-9, 2015.

[7] M. A. Shomad and M. Shahar Mushfi, "Analisis pengaruh variasi elektroda las e6013 dan e7018 terhadap kekuatan tarik dan kekerasan pada bahan baja ss 400 ," Din. Tek. Mesin, vol. 7, no. 2, pp. 73-79, 2017, doi: 10.29303/d.v7i2.156.

[8] A. Pamungkas et al., "V Pada Baja Karbon Rendah Menggunakan Elektroda Low," 2009
[9] Y. Purwaningrum, "Karakterisasi Sifat Fisis Dan Mekanis Sambungan Las Smaw Baja a287 Sebelum Dan Sesudah Pwht," Teknoin, vol. 11, no. 3, pp. 233-242, 2006, doi: 10.20885/teknoin.vol11.iss3.art7.

[10] H. S. Raharjo and R. JP, "Variasi Arus Listrik Terhadap Sifat Mekanis Sambungan Las Shielding Metal Arc Welding (Smaw)," Simp. Nas. RAPI XI FT UMS, pp. 93-97, 2012.

[11] P. R. M. Anggoro, "Pengaruh Variasi Sudut Kampuh Dan Kuat Arus Terhadap Struktur Mikro Dan Kekuatan Bending Hasil Sambungan Las Smaw Baja Karbon Rendah,” pp. 3-4, 2017.

[12] Sukaini, Teknik Las SMAW 2. 2013.

[13] T. Triana, M. Kamil, and Y. M. Zulaida, "Pengaruh Variasi Elektroda dan Arus Listrik Pengelasan Tehadap Catat Las dan Sifat Mekanik Pelat Baj Aplikasi Lambung Kapal," J. Tek. Mesin Untirta, vol. IV, no. 2, pp. 50-55, 2018.

[14] Y. Winardi, F. Fadelan, M. Munaji, and W. N. Krisdiantoro, "Pengaruh Elektroda Pengelasan Pada Baja AISI 1045 Dan SS 202 Terhadap Struktur Mikro Dan Kekuatan Tarik," J. Pendidik. Tek. Mesin Undiksha, vol. 8, no. 2, p. 86, 2020, doi: 10.23887/jptm.v8i2.27772.

[15] A. Setiawan and A. Yuli, "Analisa Ketangguhan dan Struktur Mikro pada Daerah Las dan HAZ Hasil Pengelasan Sumerged Arc Welding pada Baja SM 490," J. Tek. Mesin, vol. 8, no. 2, pp. 57-63, 2006, doi: 10.9744/jtm.8.2.pp.57-63. 
Minto/MATRIK. Vol.XXII, No.1, September 2021, Halaman 45 - 54

(Halaman ini sengaja dikosongkan) 